\title{
Being Mafia Children: An Empirical Transgenerational Research
}

\section{Serena Giunta}

Docente Cattedra "Analisi dei fenomeni devianti", LUMSA, Libera Università Maria Santissima Assunta, Dipartimento di Giurisprudenza, Roma, Italy

Giuseppe Mannino

Coordinatore Corso di Laurea Magistrale in Programmazione e Gestione delle Politiche e dei Servizi Sociali, LUMSA, Libera Università Maria Santissima Assunta, Dipartimento di Giurisprudenza, Roma, Italy

Cinzia Bizzarri

Interna Cattedra "Analisi dei fenomeni devianti", LUMSA, Libera Università Maria Santissima Assunta Dipartimento di Giurisprudenza, Roma, Italy

\section{Giuliana La Fiura}

Interna Cattedra "Analisi dei fenomeni devianti", LUMSA, Libera Università Maria santissima assunta, Dipartimento di Giurisprudenza, Roma, Italy

\section{Doi: 10.2478/mjss-2018-0018}

\begin{abstract}
Our empirical study aims at understanding and analyzing whether and how the way in which the "sons of Mafia" consider their own family and the society in general has changed over time. The psychological study is based on a sample of 11 subjects all sons of the Mafia men divided according to a generational variable, i.e. these two ranges of age: 17-28 and 39-62. The data obtained from the interviews were analyzed using the Grounded Theory method. From the comparison these elements emerged: first of all, the subjects have a distinct perception of these three different areas: - family, and especially the bond with their fathers; - society, represented mainly by the relationship with peers; - Mafia, specifically in relation to the value codes of this criminal organization. The analysis of these areas has allowed us to give a cross-reading of the Mafia phenomenon outlining the differences in the way in which the present generations and the past ones live and perceive it.
\end{abstract}

Keywords: Sons, Mafia, Psichology, empirical study, values.

\section{Introduction}

This study moves from the studies conducted over the past twenty years on the psychology of the Mafia (Lo Verso et al., 1999; Lo Verso \& Lo Coco, 2003; Lo Verso, 2013; Lo Verso et al., 2013; Giorgi et al., 2010; Giunta et al., 2016; Giunta \& Lo Verso, 2012; Mannino et al., 2015; Mannino \& 
Giunta, 2015; Schimmenti et al., 2014; Scalia, 2016; Sergi, 2017) and following a psychodynamic investigation and, specifically, a group-analytical method (Lo Verso \& Di Blasi, 2011), considers the Mafia not only as a criminal system but also as a psycho-anthropo-cultural organization with a fundamental role in the construction of individual and family identity.

From the data in literature, family in the mafia culture is seen as a strong institution which has the task of protecting those who are part of it. And family is the only model that the individuals belonging to Mafia have to adapt to the life of collectivity (Pellerone et al., 2017).

Within this phenomenon there are some particularly important elements: the mafia family has a rigid organizational structure which is also the source of its strength and its own power. This structure rests basically on the distinction between the "inside", which protects and helps, and the "outside", alien and threatening.

And inside this well-configured organizational structure the roles of the family members mother, father and children - are well outlined.

The mother educates her children giving them the values of the mafia culture, in a condition of acceptance of the family hierarchy, preventing them from developing autonomy and keeping them forever tied to herself; the father, mostly idealized, is the model to imitate, provides rules and values; the child is educated to the code of silence, to show virility, strength and opposition to the legal power.

Phenomena such as that of the "repentant Mafiosi" (pentitismo) and the harsh State repression have resulted, however, in recent years, in profound changes in the Mafia organization, also favoring significant transformations within the family model. In fact, the image of the father as a "man of honor" has considerably changed: the role of the mythical father is likely to have been belittled by TV and newspapers which rather have been describing him as a criminal, someone at large or in prison. In other words, the idealized father has lost his power, showing its weaknesses: "the all-powerful hero becomes fragile, dies, is arrested, collaborates, is hurt, is afraid"(Lo Verso et al., 1999).

In the past the men of Mafia didn't have these problems: hardly ever a "man of honor" was sentenced to life imprisonment and even in prison he was still respected; the son was not obliged to accept his father's absence. Today, however, the structure of the mafia family may be challenged by the heavy sentences imposed by the courts.

A further consequence of this process is the changing role of women / mothers (Schimmenti et al., 2014) who, as a result of "the forced absence " of their husbands, are the sole responsible for the family management. It is up to them, therefore, to take important decisions about the education of the children, before mainly subject to the paternal authority.

The children, on the other hand, live in a state of constant ambiguity due to their belonging to families whose values are completely different from the ones of the society in which they have to live. "The teenagers who come from a mafia family have nowadays to face today the dramatic task of having to choose between passively accepting the expectations of the clan but having to deal with the "new" that has infiltrated even into his psychic world, or otherwise refusing their roots, but abandoning a part of themselves as well as accepting the family ostracism or worse their vengeance" (Lo Verso \& Lo Coco, 2003).

And this latter possibility, namely to abandon the security of the family clan (which in any case is closed and remains an "island" inside the society) in order to open up to new ideas and to the possibilities of the changing society, may represent a milestone for the children, for them to build up their own identities (Mannino \& Giunta, 2015; Mannino \& Caronia, 2017; Mannino et al., 2017; Mannino, Giunta \& La Fiura, 2017)

This important objective is achieved with the help of the peers who, at this stage, represent the bridge that unites the family to the community. Being part of a group of peers, sharing their values and rules means, for a teenager, to feel secure and protected. Up to this moment we can say that within the Mafia families all this has been forbidden because of the presence of "archaic" values that clash with the "modern" values adopted by the other teenagers (Mannino et al., 2015); that is the reason why the mafia families don't want their children to be part of a society so different from the "already known" which is represented by the family itself; that is why the children of Mafia families are unlikely to establish real connections with the peers who do not belong to the world of 
the criminal organization (Gullo et al., 2015). How can we reconcile the archaic and the modern, the "sacred" and "profane"? In these families there is an attitude of closure and, above all, mistrust towards what is "outside" the organization itself.

This is the basis of our research: the understanding and analysis of how the representation of family and society which the "sons of the Mafia" have has changed.

\section{Methodology}

Having noticed that there have been profound internal changes in the Mafia families, that the teenagers "have actually entered the world of the peers" (Zizzo, 2002), the objective of this study is to explore and understand how family and social relationships are perceived and represented according to the generational differences.

This study was conducted using a semi-structured interview created on purpose and aimed at exploring the following areas: family, particularly the relationship with the father; society, represented mainly by the relationship with the peers; the Mafia, even through the interpretation of some common Sicilian sayings proposed by the interviewer: "nuddu ammiscatu cu nenti" ("nobody mixed with nothing" which is the contemptuous definition of an individual with "no honor"), "calati iuncu ca passa la china" ("bow down, cane, the flood is coming" which means that in difficult times it is better to wait) "nenti sacciu and nenti vogghiu sapiri" ("I know nothing and nothing I don't want to know").

The sample, selected through a non-probability, non-random sampling, consists of 11 subjects, all of them belonging Sicilian and sons of Mafia men, divided according to the generational variable:

- 7 people aged between 17 and 28 (2 males and 5 females): 3 the sons of men currently in prison, one of a fugitive, one of a Mafia man who was killed, one of a mafia man under house arrest;;

- 4 people aged between 39 and 62 (1 male and 3 females): 3 children of deceased Mafia men, 1 son of a Mafia man under house arrest.

The data obtained from the interviews were analyzed using the Grounded Theory method ${ }^{21}$.

The method finds its origins in the field of sociological research and is inspired by the interpretative paradigm, or attempts to provide an explanation of the processes that lie behind a given phenomenon, focusing on data rather than on theories (Glaser \& Strauss, 2009).

The established theory uses, for the purposes of the analysis, three phases of coding:

- Open Encoding, which assigns labels to phenomena, thus forming the concepts that are then grouped into categories through a "funnel" (from phenomena, concepts, categories). In this case sampling is open;

- Axial Encoding, the most specific phase in which to identify the underlying relationships to the categories identified in the previous phase, by using the paradigmatic model (a. causal conditions, b. phenomenon, c. context, d. intervening conditions, e. action strategies, f. consequences).

- Selective coding, defining the most generic, abstract, and predominant categories to which all other categories are linked through relationships. It is a superior level of abstractness, which leads to the formulation of theory (Glaser \& Strauss, 2009).

Two independent judges, followed by a careful evaluation of the answers, came to the common decision to construct thematic-conceptual maps:

1) Family area: relationship between children, family and society to the range 17-28.

2) Family area: relationship between adult, family and Mafia phenomenon to the range 39-62.

3) 3 )Values for the range 17-28 and the differences with the past ones

\section{Analysis of Data and Results}

This study highlighted family relationships inside the Mafia context in relation to the feelings directly experienced by the people selected in the sample.

Up to now, the knowledge of the families belonging to "Cosa Nostra" was based mainly on 
indirect sources, the testimonies of judges and people collaborating with the police which, although valuable, has provided only partial information, without the emotional and affective dimension of a direct experience.

The collaboration of these people belonging to Mafia families allows, however, to understand the real meaning of being born and growing up in a Mafia family context.

In the following, to analyze the answers to the interviews, we will present the thematicconceptual maps we have built following the grounded theory of Glaser and Srauss (2009).

The maps have the purpose of explicating, clarifying and offering an immediate display of the most significant elements obtained following the Grounded Theory phase: the "selective coding" phase, defining the most generic, abstract, and predominant, to which all the other categories are linked through relationships.

\section{Family area:}

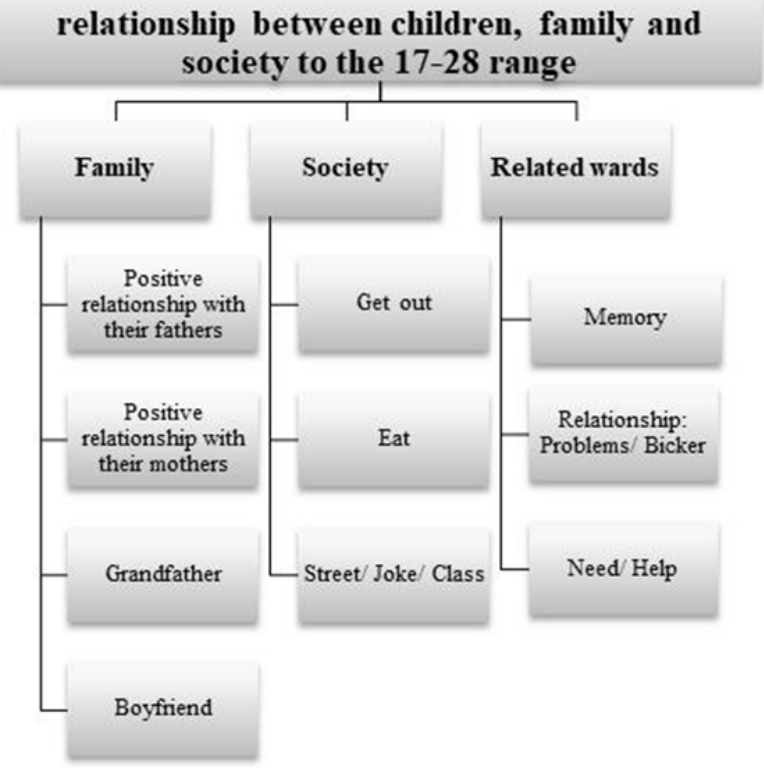

Map 1. Family area: relationship between children, family and society to the range 17-28.

As can be seen from the map "Family area: relationship between children, family and society to the 17-28 range" the study participants includes in the family concept only the most intimate components of the nucleus: parents, brother and grandfather. It is interesting to note that in this case the male component is greater than the female one. They also claim to have a good relationship with their father. Participants also stated that they associate social aspects with aspects like eating, leaving the home environment, staying in the street, or even their own classroom. The words that are most used in relation to family and society are: memory, relationship (which can be problematic and sometimes raise quarrels), need and help.

Some interview abstract:

"My relationship with my father has always been good, I love my father, the thing that I don't like is that I wanted a father with a normal situation, as every daughter wishes, it isn't nice to see your classmates with their daddy and you always without, even on Sundays, when usually every child is looking forward to going out with his/her own daddy, I was always at home alone with my mom".

"Even if a member of this association, my father was trying to divert young people of $x x x x x x$ who 
wanted to enter the association, which brings only harm. A beautiful relationship, whereas before my father was a person ... I always considered him as a bad person, I don't know, but my father was an introvert more than anything else, but not since we've had these problems".

"With my mother I have a very nice relationship, we talk about everything, we are very close. With my father since he has been in prison we are more united, I found out things about my father that I didn't know; I think not all fathers have this relationship with their children. My family is a very united family, I have a good relationship with both my parents".

"I have just one brother, we have a good relationship, we speak a lot even though he is far away, we trust each other, we have a beautiful relationship, we call each other every day, a beautiful relationship. I don't understand what it means ... if my father ... maybe there were secret, but I don't remember because my father for four years hasn't been xxxxxxx".

"Anyway, the relationship with my little brother, say that he didn't know my father, because he left when he was just a few months old, so their relationship was born when he came back home. So he couldn't compare the past situation with the present one.. My mother was always around seeing lawyers and looking after her children. Yes, he's changed in a negative way, he has too many prejudices about people, he's almost paranoid".

"Then I came home and I saw my mother and the others who were crying, screaming. My brother, the eldest, took me in his arms and held me in a strong hug, then I heard that my father was dead. At first I couldn't accept it, I tried to find a reason for all that pain, but I couldn't. The pain was too great, and I was just a little girl, I was eleven".

We noticed that the children belonging to the 17-28 range are the ones who have a positive relationship with their fathers; they talked about the special bond they have with their dads; they also claimed they firmly believe in the innocence of their fathers and they don't consider them responsible for the decision to become members of "Cosa Nostra".

The words of the people selected describe a very positive paternal figure, caring and attentive fathers, who have always respected everyone, trying to lead their children, and young people in general (as one of the interviewees emphasized), on the right way, to prevent them from committing bad mistakes.

Although physically absent, therefore, these fathers are of great emotional importance. The idealization of the absent father (Lo verso et al., 1999), a typical feature characterizing the initial phase of therapy with adolescents belonging to mafia families, could be understood through a careful analysis of what psychologically characterizes young people belonging to range17-28.

It is interesting to note that the young people belonging to this age group usually have to deal with the search for their own identity and are involved in a socialization process. It is, therefore, a complex and significantly difficult phase of their lives in which they have to build up "an image of themselves as individual and as a part of a social group" (Menarini \& Pontalti; 1993). Building your identity is not simply a sterile acquisition of rules or social values; the person has to be willing to evaluate, in terms of emotional meanings, the logic of the change.

But what is the role of family at this developmental stage of the subject?

If this transformation process happens inside the social group, on the other hand family has the important task of attributing value to the social interactions and of providing cultural bases for the children.

In other words it is family that transmits norms and values that will be useful to live and interact in the world "outside", to socialize and to find other dimensions of life.

Family "has a fundamental role in the transgenerational transmission of the values system [...], it is the element that provides interpretative codes and which conditions the assimilation of them" (Menarini \& Pontalti; 1993).

Teenagers, however, can still process and question the cultural background provided by their families, thus developing a creative capacity, that is to say, developing the ability to create something that is more of what was transmitted to them, giving their personal contribution.

Actually, this process of deconstruction and construction is functional to the formation of the individual identity: the subject, during the difficult path that will lead him to shape his own identity, will have to choose between accepting, totally complying with, the cultural bases within which he/she has been educated, using in his/her life the norms and values transmitted by his/her own family, or revisiting what learned in a creative way building up his/her internal groups (autos) 
(Napolitani, 2006; Lo Verso, 1994; Lo Verso, 89).

In this regard Napolitani (2006) argues that identity is the product of an insertion of external psychological elements on the individual's psyche, with all its peculiarities, its natural disposition, its cognitive and expressive potential.

The insertion of "non -self" parts, which is pathological in the case of the biological identity and often cause of the phenomenon of rejection (graft), is functional and important for the psychological identity. Precisely for this reason man is, according to Napolitani (2006), a "being in relation with"; being also the product of more "groupalities". This term is used to emphasize that each of us constantly internalize different group contexts, from the first one which occur more frequently, namely the family. Family predisposes for the newborn children a kind of script that they will have to learn and interpret during the course of their existence.

Very often, however, family expectations become a cage from which it is difficult to escape. And this is particularly true for the Mafia families, in which trying to disengage is considered as treason, a sort of denial of the family roots and an effort to acquire values different from those provided by the family context; that is the reason why "untie", in these families, is so difficult.

There is here an analogy with another concept usually used for different contexts: the conflict of loyalties.

Conflict of loyalty is that feeling experienced by a child when he has to choose between two divorced parents, when he has to take a position that will put him inevitably against one of the parties.

The same situation is to be faced by those teenagers who have to choose between the family values to be accepted passively or the values proposed by the society in which they live and meet the other teenagers.

Having not yet acquired the ability to deal with contradictory, distinct and often conflicting parts of the their self, teenagers wander looking for certainties and strong reference points.

Therefore, three distinct relational configurations might be described: the social teenagers who want to be recognized by and comply with the society in which they live, detaching themselves from their families; the family teenagers, devoted to their family group, unrelated to the social world (belonging to a "fundamentalist" type system, such as Cosa Nostra, these teenagers have great difficulties to disengage from family expectations on them); and finally, the teenagers in transition, who, live in an ambiguous, undefined position because they are unable to find the way to combine the commonly accepted values with those of their families (Profita et al., 2007).

The latter category seems to be representative of some of Mafia families' children. Till a few years ago, however, most of Mafia families' younger members belonged to the second category of the the family teenagers:i.e. they passively accepted what the family taught them, blocking, therefore, an important stage in the process of the creation of a personal identity. Family provides its members with the tools to learn how to classify events and to create among these meaningful connections. However, if the individual does not try to develop his/her own ability to reach a real social autonomy, he/she runs the risk to remain entangled into the family context, in a world already thought for him/her by others.

In this regard, the literature tells us that it is impossible or even unthinkable for these teenagers to leave the Mafia families in order to be part of some other social unit (Giunta et al., 2016). And it is sure that detaching from the strong Mafia family connections, opposing its binding codes transmitted by the family members and developing the ability to think in a different way, creates anxieties and conflicts, can create fear and anxiety and even cause deep divisions.

However, our research provides some partially divergent results, drawing a dividing line between what happened in the previous generations, and what happens today.

Whereas in the past the young belonging to a Mafia family could not break free from it, it is now easier to have the feeling to be part of the general society, having the perception to be "normal" and not different from the others.

This is also partly due to the changes concerning the "roles" within the family: such as the role played by the mother, once a sort of guardian of family honor and today a significant figure for these children in their effort to be part of the general society. She is the one who gives her love to her children unconditionally, despite the difficulties. The absence of the husband "obliges" the 
mother to assume a role of paternal transmission of rules and values, legitimating her authority.

This is an important and innovative aspect, if we think that in many Cosa Nostra families the uncle was invested of the task of "educating" the children in the absence of the father (Giunta et al., 2016).

Despite what has been said, for the children of the 17-28 range the Mafia is considered as an absolutely phenomenon. The younger children consider themselves as totally alien from Cosa Nostra world, even if they do not have any criticism towards their families, they seem unable to admit any responsibility of their fathers, not the involvement of their families in a mafia system which they feel very distant from their lives.

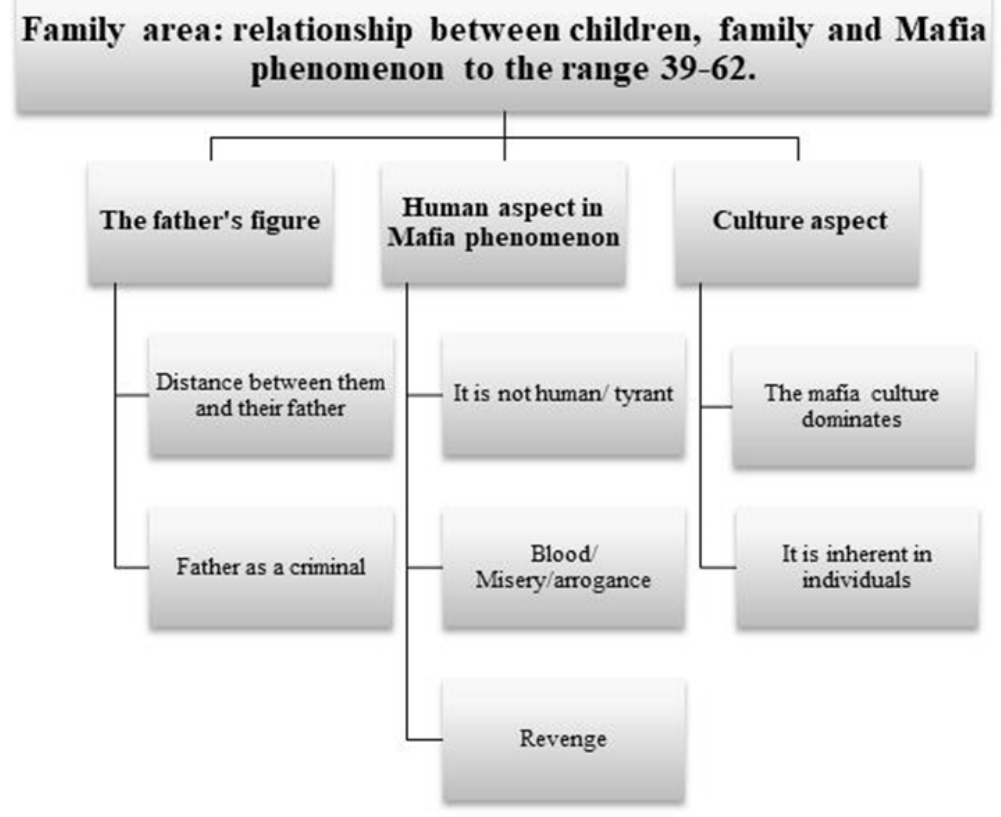

Map 2. Family area: relationship between children, family and Mafia phenomenon to the range 3962.

Unlike younger children (range 17-28), those in the 39-62 range show a greater awareness about their being part of Mafia and about the position of their fathers in this criminal organization.

Further evidence of this is the emotional distancing that emerges from their words which clearly has a defensive purpose. In fact, it is by using an intellectual perspective that they manage to distance themselves from a world still close to them.

Children belonging to the 39-62 range have highly conflictual relationship with their fathers.

Disengaging from the familiar mafia, or colluded with the Mafia world, giving a new significance to the system of values learned within their family context have been difficult and painful for them, but their courage and determination have allowed them to not surrender to the threats and violence. After a long time, overcoming their anger, they could also re-evaluate the paternal figure.

In this regard another aspect of interest is that the children belonging to the 39-62 range, describing their current family situations, talk about happy and serene contexts, whereas they have an totally different perception of their family of origin. The children belonging to the 17-28 range, yet instill living within the family of origin, describe situations of great suffering.

The most significant elementary contexts extracted are: 
"When you were talking a few minutes ago about the human aspect of the Mafia... but where is the human aspect of the Mafia, for an example $x x x x x x$ as a mafioso had to refuse the ritual of Mafia oath just to try to recover a minimum of humanity on this thing here. Because, for sure, my father was killed there, see, he didn't die in a "car accident", he was killed".

"A bad dream, right. I imagine a catastrophic landscape in some ways always referring back to that, what the mafia does, a landscape that I just cannot describe; the ugliness that is the ugliness of this veritable landscape made up of blood, misery, arrogance, indifference, roguery, illicit enrichment".

"Ok let's talk about the human aspect of this thing, that is, for example, the figure of my father, afterwards we reevaluated him because in the last period of his life some things happened ... things which others did to him in some ways, because we, even after he was ... even after his death ... we had considered him as a tyrant, the person who repudiated $x x x x x x x "$.

"Revenge not only victory, we can talk about revenge because a person performing a certain kind of activity, who is able to keep alive the figure of a killed brother, in this case of xxxxxx, keeping it alive in the true sense of the term, because the regime's culture tried to remove this figure, which is very inconvenient".

"About the fact that I mentioned a few moments ago, because this is a country dominated by the mafia culture, here the mafia culture dominates, but it dominates in a certain way, that is our culture, the culture of legality, of civil engagement, of the break with the Mafia belongs just to a minority and $x x x x x x$ is just that, people that still are unable to understand".

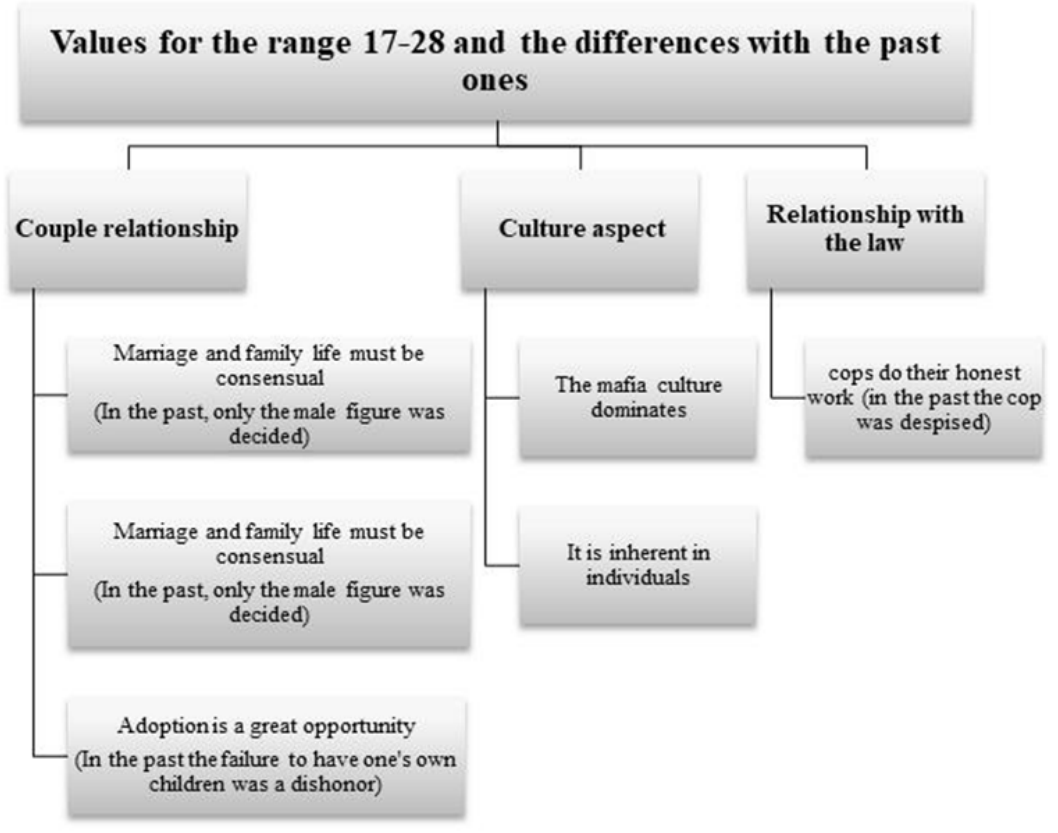

Map 3. Values for the range 17-28 and the differences with the past ones

The map is characterized by words that are related to the 17-28 generation and refer back to the family context (marry, help, live, uncle, marriage, family, keep away, respect, children, familiar, church, live, courage, wife, maternal, death).

The analysis that follows, gives us the opportunity to understand how the values attributed to the family have changed from generation to generation.

In fact, the values that the younger children attach to family are completely different from those that once characterized Mafia families. In the past for Cosa Nostra "the honor, intended as the male control on the faithfulness of a woman, was untouchable (an unfaithful woman, whether wife or girlfriend, was to be killed); having relationships with or being relatives of members of law 
enforcement was taboo ("cornuto and sbirro"- in Italy it is a way to insult someone whose wife was unfaithful; "sbirro" is a depreciative term used for "cop"-was the worst insult that a mafioso could receive and in this case he was entitled to kill, on the spot, the who had dared to offend him in this manner); homosexuality was a mistake to be totally banned and the education of the children, especially daughters, followed very strict and precise standards, and adoption was rare in this kind of families" (Lo Verso \& Lo Coco, 2003).

But today, there is, as it seems, a greater flexibility. In fact, the interviews with the cooperating witnesses reveal a different view on these changes, "marriage and family life must be consensual, children can be autonomous, cops do their honest work, divorce is a problem concerning only the couple involved "(Lo Verso \& Lo Coco, 2003). As it appears from the most significant elementary contexts the children belonging to the 17-28 range have opinions in line with such an emancipation.

"[...] because it is a horrible context; nowadays, my father can talk, because before even with us he couldn't. Today he tells us, "when I started to be part of this organization, the values, say "values", were the respect, which was for an example that you had to leave your wife alone even if she was pregnant and about to give birth if any of these men of honor needed you, you had to help them".

"I would love to get married with my boyfriend, and I have a job that would engage me only in the morning in order to be able to finally do what I want and also in the future to dedicate myself to my children. About separation I think it's a good thing, because if two people do not get along, it is better that you leave rather than continue to fight".

"About adoption I think it's a good thing. I'm not married, but if I realize that I can't have my own children, I think I'll adopt a child right away, because for me family with children is important, even if it's not your child, but if you adopts him or her when he/she is very little".

A further element of interest is that some of the words used by participants (for example: typical expression, community center, school, fighting etc ...) were influenced by the questions asked by the interviewer: "What does the saying "Nuddu ammiscatu cu nenti" (Sicilian expression which literally is "Nobody mixed up with nothing") mean?."

"Nuddu ammiscatu cu nenti" is a typical Sicilian expression in which there are two negatives: nobody and nothing. This expression is used to describe an individual who counts for nothing within the mafia organization; one that is thought to have no "honor" and that therefore "doesn't deserve to live."

Through the analysis of this item we have the opportunity to understand if the Mafia children still support or not the Mafia idea of a hierarchy in terms of "honor" among different subjects, in other words if they agree with the idea that there are "men of honor "and men who can be considered as "Nobody mixed up with nothing".

In this regard the children belonging to the 39-62 range consider this expression a typical mafia expression; they seem not to agree with the meaning of this expression and despise those who do; people's dignity cannot be trampled, the feeling of respect towards the others is an important value; no man can be considered "nuddu ammiscatu cu nenti."

The interpretations given by the children belonging to this range are clear and unambiguous and, above all, very different from those provided just a few years ago by people close to the mafia world.

In a sense, these children are witnessing a decline of the traditional idea of strength related to Cosa Nostra. The father, who became a cooperating witness or is missing because was killed or hides to avoid imprisonment, leaves a void filled with disillusionment about the principles of which he was the guarantor; if the children are still young, the only thing which remains is the affection and the idealization which are due to a father, not related to his being a member of the Mafia organization.

\section{Conclusions}

Comparing the two ranges $(17-28 ; 39-62)$ and taking as a reference the six transpersonal levels it has been to better understand the perception these "children of Mafia" have of their relationship 
with their family and with society as a whole. When the values learned within the family context are significantly different from the values commonly accepted by the rest of the society, the subject may experience a strong ambiguity.

The analysis of the interviews conducted in this research shows that younger children (range 17-28) seem to be still strongly influenced by their families and distant from the values of the general society. For them, their families and the "known" context are reassuring elements, emotionally closer to them. What is "not known", the world outside their family context, is perceived as alien, different and distancing.

On the contrary, the children belonging to the 39-62 range seem to be closer to the values of the "outside world", of society in general. Unlike the younger children, they possess strong civic principles and values which are against Mafia; they seem to be aware of having been part of this criminal organization and to try to distance themselves from it.

This empirical research, thanks to the testimonies of the Mafia children, offers a cross-reading of the phenomenon giving us the chance to understand how the phenomenon has been changing over time in its values, its hierarchy of roles, in other words in its structure.

The Mafia families find much of their strength and their power within their structure, in the differentiation of roles and in the transmission of their values.

Today we are witnessing a complex change that has started from the family (Francini, 2014) context and then has also affected the social domain: the father figure considered as man "of honor" has been more and more challenged by the sentences imposed by the courts and by the public opinion that describe these "men of honor" as a criminal. Moreover, the forced absence of the fathers has given more liberty to the mothers who have taken on, over time, a more important role in the care and in the education of the children.

These children while trying to build up their identity were asked to choose whether or not to comply entirely with the mafia values which have been transmitted to them by the family, or embrace new values disengaging from the family; i.e. they have had to choose between the "known", the family, and what is not known, the general society.

This choice as we can imagine is particularly difficult. In fact, in the past there was no record in literature of such a choice, which was considered impossible for mafia children.

In recent years the situation has been changing: more and more young people, in fact, are able to distance themselves from their own mafia family background to be part of the social world by embracing the same values of the others.

Given the results obtained, this study assumes an important value, if we think about the great difficulty in finding such a sample of subjects who are not usually helpful and willing to cooperate. And this difficulty is even more comprehensible if we think that, within the mafia context, the code of silence is generally respected as it would be an indisputable, even if unwritten, law.

Silence, indeed, is a basic element of the Mafia influence and identity which draws its strength from the absence of communication: silence, that is not talking about mafia and about its members, is, on the one hand, one of the main internal strengths of the mafia phenomenon and, secondly, a barrier of defense from everything that is external to the phenomenon itself. The code of silence, in other words, is useful to safeguard the interests of those who constitute this criminal organization. Those who break this code become an accomplice of "the outside", of the State, and are considered, therefore, as enemies by Mafia and by its members. The Mafia organization will consider them as "infamous", the same judgement is given about the ones who collaborate with police, precisely because they broke the silence: they are said to have "spit in the dish in which they ate"; they are sort of traitors, having broken the supreme law of silence.

That said, it is easier to understand why it was difficult and challenging to find Mafia children willing to "talk", to tell their stories and to talk about their choices

The people of the sample, in fact, have over time been subjected to this law, to its strength. All of them have experienced on within themselves the strength of the embrace of their "families", within which one feel protected but also isolated. However some of them have been able to break through this defensive wall, breaking the silence, which is still one of the most important laws of survival of the mafia itself. 


\section{Limitations}

We consider three significant limitations to these findings. First, the sample is not large: this is due to the fact that it is very difficult to find Mafia children willing to speak of their story.

Second, the international bibliography is poor: few are indeed the authors who deal with Mafia, outside the Italian context. For these two reasons, conducting a study on Mafia children is really difficult.

\section{References}

Francini, G. (2014). Il dolore del divorzio. Terapia, mediazione e cura della famiglia separata: Terapia, mediazione e cura della famiglia separata. Milano: FrancoAngeli.

Giorgi, A., Giunta, S., Coppola, E., \& Lo Verso, G. (2009). Territori in controluce. Ricerche psicologiche sul fenomeno mafioso. Milano: Franco Angeli.

Giunta, S., \& Verso, G. L. (2012). Nel nome del padrino. International Journal of Psychoanalysis and Education, 4(2).

Giunta, S., Verso, L., \& Mannino, G. (2016). II Mondo mafioso: Tra pratica clinica e interventi nella polis. Società Editoriale ARPAnet, Genova, ISSN 2037-5727

Glaser, B. G., \& Strauss, A. L. (2009). La scoperta della Grounded Theory. Strategie per la ricerca qualitativa. Roma: Armando Editore.

Gullo, S., Coco, G. L., Di Fratello, C., Giannone, F., Mannino, G., \& Burlingame, G. (2015). Group climate, cohesion and curative climate. A study on the common factors in group process and their relation with members attachment dimensions. Research in Psychotherapy: Psychopathology, Process and Outcome, 18(1), ISSN: 2239-8031, DOI: 10.7411/RP.2014.023.

Lo Verso G. (2013). La mafia in psicoterapia. Milano: Franco Angeli.

Lo Verso G., Coppola E., Giorgi A., Giunta S. (2013). I vissuti degli psicoterapeuti che lavorano con i pazienti appartenenti al mondo mafioso. Ulteriore approfondimento delle psiche mafiosa. In Lo Verso G. (2013). La mafia in psicoterapia. Milano: Franco Angeli.

Verso, G. L., \& Ruvolo, G. (1989). Clinica della gruppoanalisi e psicologia. Torino: Bollati Boringhieri.

Lo Verso, G. (1994). Le relazioni soggettuali. Torino: Bollati Boringhieri.

Verso, G. L., \& Di Blasi, M. (2011). Gruppoanalisi soggettuale. Milano: Raffaello Cortina.

Verso, G. L., \& Coco, G. L. (Eds.). (2003). La psiche mafiosa: storie di casi clinici e collaboratori di giustizia (Vol. 37). Milano: FrancoAngeli.

Lo Verso G., Lo Coco G., Mistretta S., Zizzo G. (1999). Come cambia la mafia: esperienze giudiziarie e psicoterapeutiche in un paese che cambia (Vol. 18). Milano: FrancoAngeli.

Mannino, G., Giunta, S., Buccafusca, S., Cannizzaro, G., \& Lo Verso, G. (2015). Communication Strategies in Cosa Nostra: An Empirical Research. World Futures, 71(5-8), 153-172.

Mannino, G., \& Giunta, S. (2015). Psychodynamics of the mafia phenomenon: psychological-clinical research on environmental tapping and white-collar crime. World Futures, 71(5-8), 185-201.

Mannino, G., \& Caronia, V. (2017). Time, well-being, and happiness: A preliminary explorative study. World Futures, 73(4-5), 318-333.

Mannino, G., Giunta, S., \& La Fiura, G. Psychodynamics of the Sexual Assistance for Individuals with Disability. Sexuality and Disability, 1-12.

Mannino, G., Montefiori, V., Faraci, E., Pillitteri, R., lacolino, C., Pellerone, M., \& Giunta, S. (2017). Subjective perception of time: Research applied on dynamic psychology. World Futures, 1-18.

Menarini, R., \& Pontalti, C. (1993). L'adolescenza nell'universo dei valori. Vita e pensiero.

Napolitani, D. (2006). Individualità e gruppalità. Ipoc Press.

Pellerone, M., lacolino, C., Mannino, G., Formica, I., \& Zabbara, S. M. (2017). The influence of parenting on maladaptive cognitive schema: a cross-sectional research on a group of adults. Psychology research and behavior management, 10, 47. Doi: 10.2147/PRBM.S117371.

Profita, G., Ruvolo, G., \& Lo Mauro, V. (2007). Transiti psichici e culturali, una prospettiva culturalista sulle dinamiche dei gruppi mediani ed allargati. Milano: libreria Cortina.

Scalia, V. (2016). The Mafia in the Post-Fordist Era. In Crime, Networks and Power (pp. 25-40). Springer International Publishing.

Sergi, A. (2017). Conclusion: A Socio-behavioural Approach in Policing the Mafia-Organised Crime Spectrum. In From Mafia to Organised Crime (pp. 289-307). Palgrave Macmillan, Cham.

Schimmenti, A., Giunta, S., \& Verso, G. L. (2014). Mafia Women: A Study on Language and Mental Representations of Women Engaged with Mafia Members. International Journal of Criminology and Sociology, 3, 267-274. 
Zizzo, G. (2002). Adolescenza e psicodramma analitico. Gruppi. Milano: Franco Angeli. 